\title{
The cooked meat-derived mammary carcinogen \\ 2-amino-1-methyl-6-phenylimidazo[4,5-b]pyridine (PhIP) elicits estrogenic-like microRNA responses in breast cancer cells
}

\author{
MD Papaioannou ${ }^{1}$, C Koufaris ${ }^{1}$ and NJ Gooderham \\ Computational and Systems Medicine, Surgery and Cancer, Imperial College \\ London, UK, SW7 2AZ
}

Correspondence to:

Nigel J Gooderham

Computational and Systems Medicine,

Surgery and Cancer,

Sir Alexander Fleming Building

Imperial College London,

London,

UK, SW7 2AZ

Tel: (+44) 02075943188

Email: n.gooderham@imperial.ac.uk

${ }^{1}$ Joint lead authors

Key words: 2-amino-1-methyl-6-phenylimidazo[4,5-b]pyridine, estradiol, estrogen receptor, miRNA, MCF-7 cells

Abbreviations: 2-amino-1-methyl-6-phenylimidazo[4,5-b]pyridine (PhIP), microRNA (miRNA), oestrogen receptor (ER), oestrogen receptor alpha $(E R \alpha)$, oestrogen receptor beta (ER $\beta)$, heterocyclic amines (HCA), 17- $\beta$ estradiol (E2), dextran coated charcoal stripped serum (DCCSS), oestrogen response element (ERE), long interspersed element-1 (L1) 
Abstract

The cooking of meat results in the generation of heterocyclic amines (HCA), the most abundant of which is 2-amino-1-methyl-6-phenylimidazo[4,5b]pyridine (PhIP). Data from epidemiological, mechanistic, and animal studies indicate that PhIP could be causally linked to breast cancer incidence. Besides the established DNA damaging and mutagenic activities of PhIP, the chemical is reported to have oestrogenic activity that could contribute to its tissue specific carcinogenicity. In this study we investigated the effect of treatment with PhIP and 17- $\beta$-estradiol (E2) on global microRNA (miRNA) expression of the oestrogen responsive MCF-7 human breast adenocarcinoma cell line.

PhIP and E2 caused widespread and largely over-lapping effects on miRNA expression, with many of the commonly affected miRNA reported to be regulated by oestrogen and have been implicated in the initiation and progression of breast cancer. The regulatory activity of the miRNAs we show here to be responsive to PhIP treatment, are also predicted to mediate cellular phenotypes that are associated with PhIP exposure. Consequently, this study offers further support to the ability of PhIP to induce widespread effects via activation of oestrogen receptor alpha $(E R \alpha)$. Moreover, this study indicates that deregulation of miRNA by PhIP could potentially be an important nonDNA-damaging carcinogenic mechanism in breast cancer. 


\section{Introduction}

The cooking of meat results in the formation of heterocyclic amines (HCA), with the most abundant one being 2-amino-1-methyl-6-phenylimidazo[4,5b]pyridine (PhIP) (Felton et al., 1986; Murray et al., 1993). In animal studies PhIP has been shown to increase the incidence of mammary and colon cancers (Ito et al., 1991). Consequently, it has been postulated that exposure of humans to HCA such as PhIP through their diet could be a major determinant of breast cancer incidence. Epidemiological studies examining the potential association of PhIP with the incidence of human breast cancer have given inconsistent results, with some studies suggesting increased risk (Sinha et al., 2000; Steck et al., 2007; Taylor et al., 2007) while others found no association (Delfino et al., 2000; Kabat et al., 2009). Elucidating the mechanisms by which PhIP can drive breast carcinogenesis would greatly facilitate the assessment and management of risk to exposed human populations.

PhIP is primarily metabolised through the action of CYP1A2 to the $N$-hydroxy derivative (Zhao et al., 1994). This metabolite is then esterified to an unstable nitrenium ion that attacks and forms adducts with guanine bases of DNA (Crosbie et al., 2000; Rindgen et al., 1995; Zhao et al., 1994). The DNA adducts can eventually lead to mutations. Indeed, in a variety of bacterial and mammalian systems PhIP was demonstrated to be a DNA damaging and mutagenic agent (Felton and Knize, 1991) (Boobis et al., 1996; YadollahiFarsani et al., 1996),(Boyce et al., 2004; Boyce, 2014). The DNA-damaging and mutagenic properties of PhIP are therefore one mechanism by which the chemical can cause cancer. Independently from its DNA damaging activity, work in our laboratory (Gooderham et al., 2002; Lauber et al., 2004; Lauber and Gooderham, 2007, 2011) and by others (Bennion et al., 2005; Okudaira et al., 2013) identified PhIP as a potent stimulator of oestrogen receptor alpha $(E R \alpha)$, but not oestrogen receptor beta $(E R \beta)$. Oestrogen induces multiple important biological responses in exposed breast cancer cells and is an established risk factor for breast cancer (Ali and Coombes, 2002). The ability 
of PhIP to activate ERa therefore represents an alternative, epigenetic mechanism, through which PhIP may drive breast carcinogenesis. However, two studies have questioned whether PhIP can indeed exert oestrogen hormone-like effects (Evans et al., 2010; Immonen et al., 2009) and therefore the ability of PhIP to act as a xenoestrogen is controversial.

MicroRNAs (miRNAs) are a class of non-coding genes that repress posttranscriptionally their target genes and are known to regulate cellular phenotypes such as proliferation, differentiation, apoptosis, and senescence. Dysregulation of miRNA has been implicated in various human diseases, including cancer (Mendell and Olson, 2012) and occurs following treatment with carcinogenic chemicals (Koufaris et al., 2012). A number of studies have reported that oestrogenic treatments result in altered miRNA expression in breast cancer cell lines (Klinge, 2012). Oestrogen regulates its target miRNA by diverse mechanisms, including the direct binding to oestrogen response element (ERE) in the promoters and enhancers of miRNA (Cicatiello et al., 2010), by affecting biogenesis and processing of miRNA (Paris et al., 2012) or indirectly through the action of its target genes (Castellano et al., 2009). Functional studies have linked oestrogen-induced deregulation of miRNA with phenotypic changes that contribute to breast carcinogenesis (Castellano et al., 2009; Chu et al., 2014; Pinho et al., 2013). Consequently, it is possible that aberrant miRNA expression induced by activation of ERa by PhIP could be an important factor in the carcinogenesis induced by the chemical. However, it should be noted that PhIP has also been reported to affect cellular pathways by mechanisms that are independent of ERa (Creton et al., 2007).

To date no published studies have investigated the effects of PhIP exposure on the expression of miRNA in mammary cells. In this study we examined the effects of exposure to this potent mammary carcinogen on global miRNA expression in the oestrogen responsive and ER expressing MCF-7 breast cancer cell line. PhIP exposure induces rapid changes in target genes and pathways (Lauber et al., 2004) therefore we chose to look at acute (4-24 h) time points. Although several studies have examined the effects of E2 on the expression of miRNA, the reported effects are inconsistent (Klinge, 2012). 
The inter-study variability is probably due to differences in time and dose of treatment, as well as the chosen cell culture conditions. Therefore, in order to investigate the degree to which the PhIP-induced alterations were associated with the oestrogen receptor, we also performed parallel treatments with 17- $\beta$ estradiol (E2). Our findings demonstrate that PhIP exposure leads to altered expression of miRNA that has a strong similarity to alterations induced by exposure to E2 and indicate that deregulation of miRNA could be an important epigenetic mechanism contributing to the carcinogenic properties of the chemical.

\section{Material \& Methods}

\section{Cell culture}

The MCF-7 cell line used here was obtained from the European Collection of Cell Cultures. The cells were routinely maintained in minimal essential media supplemented with non-essential amino acids (MEM, Invitrogen), 10\% FBS (Invitrogen), $2 \mathrm{mM} \mathrm{L-glutamine} \mathrm{(Invitrogen),} \mathrm{and} 100 \mathrm{lU} / \mathrm{ml}$ penicillin/100 $\mu \mathrm{g} / \mathrm{ml}$ streptomycin (Invitrogen) in an incubator maintained at $5 \% \mathrm{CO}_{2}$ and $37^{\circ} \mathrm{C}$. MCF-7 cells were cultured in phenol red-free MEM supplemented with $10 \%$ dextran coated charcoal stripped serum (DCCSS), $2 \mathrm{mM}$ L-glutamine, and $100 \mathrm{IU} / \mathrm{ml}$ penicillin $/ 100 \mu \mathrm{g} / \mathrm{ml}$ streptomycin. To prepare the serum DCCSS dextran-coated charcoal (Sigma-Aldrich) was first added to FBS and left to stir overnight at $4^{\circ} \mathrm{C}$. The solution was then centrifuged at $1000 \mathrm{rpm}$ for 20 minutes at $4^{\circ} \mathrm{C}$, followed by decanting of FBS. The whole process was repeated twice. Finally the DCCSS was centrifuged for 30 minutes at $3000 \mathrm{rpm}$ and filtered twice $(0.2 \mu \mathrm{M}$ filter). Dilutions of PhIP (Toronto Research chemicals) and E2 (Sigma-Aldrich) in absolute ethanol were added to each well at the appropriate dosage, with the final ethanol concentration set at $1 \%$. For control cells the media was supplemented with absolute ethanol (final concentration 1\%). All experiments were performed in triplicate. 


\section{E-Screen}

An E-SCREEN assay was performed following the method of Soto et al. (Soto et al., 1994), with modifications. Cells were seeded into 6-well plates at a density of $2.5 \times 10^{5}$ cells/well in DCSS supplemented media. The following day the media in the wells was replaced with DCSS media containing the tested compounds or ethanol vehicle. The treated cells were harvested after 24, 48 and 72 hours and cell counts were performed using a Neubauer haemocytometer and trypan blue stain (Sigma-Aldrich).

\section{RNA extraction}

Total RNA was extracted from cells using Trizol (Invitrogen), following the manufacturer's instructions. A Nanodrop ND-1000 was used to quantify the extracted RNA and evaluate the purity of the RNA solution by determining the $260: 280$ and $260: 230$ ratios. The integrity of the isolated RNA was evaluated using the RNA 6000 Nano kit (Agilent) analysed on an Agilent Bioanalyser 2100 (Agilent). RNA was used for subsequent analysis only if it had an RNA integrity number greater than eight and a 260:280 ratio greater than 2.0.

\section{MiRNA microarrays}

For the microarray experiments MCF-7 cells were treated as described previously (Lauber et al., 2004) with $10^{-7} \mathrm{M}$ PhIP, $10^{-8} \mathrm{M}$ E2 or ethanol vehicle for $4,8,12$ or 24 hours. At each timepoint total RNA was collected. The RNA was dephosphorylated by incubation with Calf Intestine Alkaline Phosphatase (CIP) enzyme and and denatured by the addition of $100 \%$ dimethyl sulphoxide (DMSO). T4 RNA ligase was then used to ligate Cyanine 3-pCp onto RNA from cells kept in control media and Cyanine 5-pCp onto RNA extracted from cells treated with either PhIP or E2. The labelled RNA was subsequently isolated with the use of Micro Bio-Spin columns (Bio-Rad). Total RNA was labelled using the miRNA Complete Labeling and Hyb Kit (Cy3 and CY5, Agilent). The same kit was used to hybridise the labelled RNA onto Human 
miRNA microarray kit V2 (Agilent). After washing, the slides were viewed using an Agilent scanner (G2505B), and the data were collected using Agilent Feature Extraction v.10.1 software.

\section{Normalisation, processing, and analysis of miRNA microarray data}

The raw microarray data files were processed and normalised in BRB-Array tools. Probes were excluded from the analysis if the intensity in the green or red channel (Cy3 and Cy5 respectively) was below 100 in both channels or if the probe size was below 10. Probe signal was averaged for replicate probes on each slide. The data were then log2 transformed and lowess smooth normalised. MiRNA were removed from further analysis if they were not flagged as present in at least $50 \%$ of samples. Due to the fact that RNA samples from PhIP and E2 treated cells were hybridized on the same arrays as RNA from vehicle treated cells, only relative miRNA expression levels were determined. In order to analyze the dataset through a statistically sound filter that accounted for the magnitude of expression change as well as for confidence intervals, miRNAs responsive to PhIP and E2 treatments were deemed those displaying greater than 1.5 fold upregulation or downregulation and at least two standard deviations distant, compared to vehicle treated cells. Hierarchical clustering analysis of microarray samples was performed using the clustering function in BRB-ArrayTools using average linkage and correlation centered

\section{Quantitative Reverse Transcription PCR (qRT-PCR)}

Total RNA was reverse transcribed to CDNA using MMVL reverse transcriptase (Promega) and oligo dT primer (Sigma-Aldrich). To quantify selected miRNA by qRT-PCR the Platinum ${ }^{\circledR}$ SYBR $^{\circledR}$ Green qPCR SuperMixUDG (Invitrogen) was used with Universal qPCR primer and miRNA specific primers at a concentration of $200 \mathrm{nM}$. The PCR was performed in an $A B I$ 7500 Real-Time PCR instrument (Applied Biosystems). The levels of the miRNA were determined by the $\Delta \Delta C_{T}$ method using $U 6$ as the internal reference. 


\section{Statistical Analysis}

Statistical analysis was performed using ANOVA with Tukey or Dunnet's posttest.

\section{Results}

\section{E-Screen for 17- $\beta$-estradiol and PhIP}

The E-screen is a well-established assay for oestrogenic activity (Soto et al., 1994). The basis of this assay is that MCF-7 cells are growth-inhibited in media containing DCCSS human serum and will only proliferate in the presence of E2 or chemicals with oestrogenic properties. In our previous study, treatment with PhIP resulted in a concentration dependent increase in MCF-7 proliferation (Lauber et al., 2004). Here we examined doses of PhIP from $10^{-11}$ to $10^{-6}$ Molar and multiple time-points (24, 48, and 72 hours). Under these experimental conditions PhIP induced non-monotonic proliferative responses in MCF-7 cells at all time-points (Fig.1A). No significant proliferative response was observed at any time-point in response to treatment with the highest PhIP dose tested here, $10^{-6} \mathrm{M}$. As expected, a nonmonotonic proliferative response was also observed for E2 under these conditions (Fig.1B).

\section{Effect of E2 and PhIP on miRNA expression in MCF-7 cells}

The doses of E2 $\left(10^{-8} \mathrm{M}\right)$ and PhIP $\left(10^{-7} \mathrm{M}\right)$ which resulted in the strongest proliferative response in MCF-7 cells in the E-SCREEN (Fig.1) were chosen for further study. MiRNA microarrays were used to profile the expression of miRNA in MCF-7 cells treated with the chemicals or with vehicle control for 4 , 8,12 , and 24 hours. After processing of the samples as described in Materials \& Methods, 723 mature miRNA were detected in the microarray data. Box plot analysis demonstrated comparable distributions for the microarray samples (Fig.2A), supporting the robust nature of the datasets. 
Hierarchical clustering analysis of the microarray samples revealed a clear demarcation of miRNA profiles for MCF-7 cells treated with PhIP or E2 (Fig.2B). Those miRNA displaying a greater than two standard deviations and a 1.5 fold upregulation or downregulation compared to vehicle treated cells were designated as responsive to chemical treatment. Using this criteria 35 miRNA out of the 723 detected were classified as responsive to E2 and 24 to PhIP at one or more of the examined timepoints (Tables 1-2). Examination of the updated version miRBase database (version 20) showed that miR-923 and miR-801 have been wrongly classified as miRNA (the former redefined as a fragment of 28s rRNA while the latter as a fragment of U11 spliceosomal RNA). Consequently, these were removed from further analysis. To verify the microarray results by an independent method we quantified by qRT-PCT the two miRNA (miR-663 and miR-638) that showed the largest magnitude of response in PhIP vs. vehicle treated cells according to the microarray data. This analysis confirmed a high degree of concordance between microarray and qRT-PCR for these miRNA (Fig.2C).

Importantly, there was a significant overlap in the miRNA deregulated by PhIP and E2 at each time-point (Fig.3A-D), with 15 out of 24 miRNA responsive to PhIP also being responsive to E2. Overall, despite the presence of some variability, the direction and magnitude of response for the majority of the miRNA were consistent across the four examined time-points (Tables 1-2 and Fig.4), indicating the role of miRNA deregulation in the observed proliferative response to PhIP. A number of the miRNA affected by PhIP have been previously reported to be regulated by oestrogen including miR-21 (Wickramasinghe et al., 2009), miR-16 (Yu et al., 2012), miR-200c (Manavalan et al., 2013), miR106b (Castellano et al., 2009), miR-26a and miR-24 (Maillot et al., 2009), further supporting the notion that PhIP has estrogenic-like activity. 


\section{Discussion}

Expanding on our previous work we showed that PhIP induced time and dose-dependent increased proliferation of MCF-7 cells (Fig.1), confirming the ability of the chemical to act as a xenoestrogen. By using a wider-range of concentrations we also showed for the first time that proliferation in the ESCREEN in response to PhIP stimulation is of a non-monotonic nature (Fig.1A). A similar non-monotonic response was also observed in response to E2 treatment (Fig.1B) in the same MCF-7 cell line. Importantly, the nonmonotonic response to both treatments was observed at all examined timepoints, supporting the validity of this response in our experimental setup. Non-monotonic responses to hormones and endocrine-disrupting chemicals, including E2, are a matter of ongoing debate in regards to their validity and relevance (Vandenberg et al., 2012) (Rhomberg and Goodman, 2012). In this study the mechanistic basis for the observed non-monotonic response to the two chemicals was not explored, but could include activation of distinct ERaindependent signalling pathways as well as negative feedback loops that could be linked with the notable decrease of the proliferative response at the highest dose for both treatments. It is therefore probable that the observed non-monotonic responses to PhIP and E2 share a similar mechanism, based on the shape of the dose-response curves.

Activity of ERa is known to affect miRNA by diverse mechanisms that include direct binding to promoters and enhancer elements to activate transcription and by affecting miRNA processing (Klinge, 2012). It was shown in this study for the first time that PhIP exposure elicits wide-spread effects on the miRNAome of a breast cancer cell line (Table 1). Importantly, miRNA that were responsive to PhIP were also affected by E2 treatment (for example miRs-21, -663, -638, -330-5p, -518C*, -574-5p, 923) (Table 2; Fig.3 and 4). The similar effects of PhIP and E2 treatments on miRNA expression that are determined here (Tables 1-2) provide grounds for PhIP driving miRNA deregulation through the activation of ERa. For at least one of the commonly affected miRNA, miR-21, it has been reported that it is transcriptionally 
regulated by ERa (Wickramasinghe et al., 2009). However, in the absence of additional experimental data it is not possible to differentiate between miRNA expression changes that are directly mediated by ERa and those that stem from secondary events. Discrimination between direct and indirect miRNA regulation by the activated ERa would require additional experiments such as chromatic immunoprecipitation. It was also observed that the majority of the miRNA affected by the treatments displayed reduced expression (Tables 1-2). A more wide-spread repression of miRNA rather than upregulation following E2 treatment in breast cancer cells is consistent with some studies (Maillot et al., 2009) (Yu and Snyderwine, 2002), but not others (Klinge, 2012). It has been suggested that the repression of miRNA by E2 is involved in the increased proliferation of mammary cells when stimulated with the hormone (Maillot et al., 2009; Yu et al., 2012).

At the same time, there were also differences in the miRNA profiles of MCF-7 cells treated with PhIP and E2, as evidenced by clustering of samples and miRNA affected by only one treatment (Fig.2B; Fig.3). A potential difference between PhIP and E2 is the DNA adduct forming properties of the former. In vivo the genotoxicity of PhIP is dependent on metabolism by the CYP1 enzymes. The MCF-7 cell line possesses active CYP1A enzymes that can metabolise PhIP to its DNA-reactive form. However, the PhIP doses used in this study are much lower than the micromolar levels that are required for such genotoxic activity. It is also the case that the miRNA affected by PhIP in this study are different to those that have been reported to be affected by DNA damage signalling e.g. the induction of the miR-34 family by p53 ( $\mathrm{He}$ et al., 2007). In fact, our study shows a stronger induction for miR-34b for E2 treated MCF-7 cells after 24 hours compared to PhIP treated cells, that could be a result of the upregulation of p53 and Mdm2 by E2 treatment (Qin et al., 2002). It is likely that distinct effects of PhIP on miRNA expression are either due to differential degrees of ERa activation or ER-independent effects of the two compounds, rather than the DNA-adduct forming effects of PhIP.

Given that miRNA deregulation can drive breast carcinogenesis (Shimono et al., 2009; Song et al., 2013) it is plausible that the ability of PhIP to deregulate 
miRNA through activation of ERa could be an important mechanism in PhIPmediated carcinogenesis and be implicated in the phenotypic consequences of exposure to the chemical. PhIP treatment has been reported to upregulate the anti-apoptotic BCL-2 in the mammary gland of rats (Venugopal et al., 1999). Interestingly, BCL-2 expression has been shown to be repressed in MCF-7 cells by miR-21 (Wickramasinghe et al., 2009), miR-16 (Yu et al., 2012), and miR-24 (Srivastava et al., 2011), all of which were downregulated by PhIP in this study. PhIP has also been shown to affect metastatic potential in vitro (Lauber and Gooderham, 2011). In this study PhIP repressed miR$200 \mathrm{c} / 141$, miRNA that are master regulators of invasiveness and metastasis (Burk et al., 2008). H-Ras, an oncogene that is mutated in PhIP-induced breast cancer (Yu and Snyderwine, 2002) is also targeted by miR-663 (Yang et al., 2013), one of the most strongly suppressed miRNA identified in this study. However, whether the miRNA deregulation identified in this study can be extrapolated to in vivo mammary tissue in exposed animals or humans is not clear. Our previous reports show that the effects of xenobiotics on miRNA profiles in vivo are highly dependent on the dose and time of exposure (Koufaris et al., 2013). Additionally, oestrogenic effects on miRNA expression are reported to be highly variable according to cell culture conditions (Klinge, 2012).

Two published studies have questioned the ability of PhIP to induce oestrogenic responses in breast cancer cells (Evans et al., 2010; Immonen et al., 2009) however, a number of observations are at variance with their conclusions. Computational receptor binding studies predict that PhIP fits the ERa (Bennion et al., 2005; Nettles et al., 2008). Oestrogenicity of PhIP has been reported in a number of different in vitro assays such as in COS-1 cells transiently transfected with ERa, activation of luciferase reporter-gene in MELN cells, and induction of proliferation in MCF-7 cells (Lauber et al., 2004; Lauber and Gooderham, 2007). The ability of PhIP to induce oestrogenicdependent responses is also supported by the work of independent labs (Bennion et al., 2005; Okudaira et al., 2013). Importantly, blocking oestrogenic signalling disrupts the ability of PhIP to induce phenotypic responses in exposed cells (Lauber et al., 2004; Lauber and Gooderham, 2007, 2011; 
Okudaira et al., 2013). Consequently, we consider it highly unlikely that the ability of PhIP to induce oestrogenic-dependent responses identified by ourselves and others is artifactual. It is also important to note that the two contradictory studies did not attempt to replicate the original findings and varied in experimental conditions such as cell type, treatment doses, exposure times, and seeding densities. A further complication is that a variety of MCF-7 sublines exist which differ in their sensitivity to oestrogenic treatments (Villalobos et al., 1995). The non-monotonic oestrogen response to PhIP (Fig.1) further emphasises the importance of dose and temporal considerations.

A recent study employing a specific assay for PhIP-DNA adducts suggested that the incidence of adduct formation in mammary tissue in humans is relatively low (Gu et al., 2012). Yet the tissue specificity of the carcinogenic effects of PhIP involves selectivity for the breast, and suggests that a predominantly genotoxic mechanism of action is unlikely. This is supported by the fact that the reported levels of PhIP exposure anticipated to occur in humans are likely to be below those shown to induce mutagenesis (Lauber et al., 2004; Lynch et al., 1992), although they are within the range of exposures shown to give rise to measurable PhIP-DNA adducts (Turteltaub et al., 1999). Doses of PhIP that are estimated to be within physiologically relevant levels have been reported to activate ERa and induce multiple effects that could contribute to carcinogenesis including increased proliferation, prolactin secretion, invasiveness (Lauber et al., 2004; Lauber and Gooderham, 2007, 2011), and long interspersed element-1 (L1) mediated genomic instability (Okudaira et al., 2013). Whilst the former studies investigating the hormonelike properties of PhIP were based on cell line models (Lauber et al., 2004; Lauber and Gooderham, 2007, 2011), importantly, Okudaira et al.,(Okudaira et al., 2013) used transgenic mice to detect in vivo ERa-dependent genomic instability caused by PhIP exposure, supporting the biological relevance of this mechanism. The data generated in the present study support these previous reports and demonstrate that in MCF-7 breast cancer cells PhIP exposure can also drive the deregulation of miRNA expression (Fig.2-3). Thus this work adds further mechanistic support to the hypothesis that life- 
long exposure to low levels of PhIP could increase the incidence of breast cancer through oestrogenic mechanisms.

\section{Acknowledgements}

MP was the recipient of a PhD scholarship from Imperial College London. 


\section{References}

Ali, S., Coombes, R.C., 2002. Endocrine-responsive breast cancer and strategies for combating resistance. Nature reviews Cancer 2, 101-112.

Bennion, B.J., Cosman, M., Lightstone, F.C., Knize, M.G., Montgomery, J.L., Bennett, L.M., Felton, J.S., Kulp, K.S., 2005. PhIP carcinogenicity in breast cancer: computational and experimental evidence for competitive interactions with human estrogen receptor. Chemical research in toxicology 18, 1528-1536.

Boobis, A.R., Gooderham, N.J., Edwards, R.J., Murray, S., Lynch, A.M., YadollahiFarsani, M., Davies, D.S., 1996. Enzymic and interindividual differences in the human metabolism of heterocyclic amines. Archives of toxicology Supplement $=$ Archiv fur Toxikologie Supplement 18, 286-302.

Boyce, A., Doehmer, J., Gooderham, N.J., 2004. Phytoalexin resveratrol attenuates the mutagenicity of the heterocyclic amines 2-amino-1-methyl-6-phenylimidazo[4,5-

b]pyridine and 2-amino-3,8-dimethylimidazo[4,5-f]quinoxaline. Journal of chromatography B, Analytical technologies in the biomedical and life sciences 802, 217-223.

Boyce, A.D., RM.; Gooderham, NJ. , 2014. The mutagenic effects of 2-amino-1methyl-6-phenylimidazo[4,5-b] pyridine in MutaTMMouse colon is attenuated by resveratrol. Toxicology Research 3.

Burk, U., Schubert, J., Wellner, U., Schmalhofer, O., Vincan, E., Spaderna, S., Brabletz, T., 2008. A reciprocal repression between ZEB1 and members of the miR200 family promotes EMT and invasion in cancer cells. EMBO reports 9, 582-589.

Castellano, L., Giamas, G., Jacob, J., Coombes, R.C., Lucchesi, W., Thiruchelvam, P., Barton, G., Jiao, L.R., Wait, R., Waxman, J., Hannon, G.J., Stebbing, J., 2009. The estrogen receptor-alpha-induced microRNA signature regulates itself and its transcriptional response. Proceedings of the National Academy of Sciences of the United States of America 106, 15732-15737.

Chu, H.W., Cheng, C.W., Chou, W.C., Hu, L.Y., Wang, H.W., Hsiung, C.N., Hsu, H.M., Wu, P.E., Hou, M.F., Shen, C.Y., Yu, J.C., 2014. A novel estrogen receptormicroRNA 190a-PAR-1-pathway regulates breast cancer progression, a finding initially suggested by genome-wide analysis of loci associated with lymph-node metastasis. Human molecular genetics 23, 355-367.

Cicatiello, L., Mutarelli, M., Grober, O.M., Paris, O., Ferraro, L., Ravo, M., Tarallo, R., Luo, S., Schroth, G.P., Seifert, M., Zinser, C., Chiusano, M.L., Traini, A., De Bortoli, M., Weisz, A., 2010. Estrogen receptor alpha controls a gene network in luminal-like breast cancer cells comprising multiple transcription factors and microRNAs. The American journal of pathology 176, 2113-2130.

Creton, S.K., Zhu, H., Gooderham, N.J., 2007. The cooked meat carcinogen 2-amino1-methyl-6-phenylimidazo[4,5-b]pyridine activates the extracellular signal regulated kinase mitogen-activated protein kinase pathway. Cancer Res 67, 11455-11462.

Crosbie, S.J., Murray, S., Boobis, A.R., Gooderham, N.J., 2000. Mass spectrometric detection and measurement of N2-(2'-deoxyguanosin-8-yl)PhIP adducts in DNA. Journal of chromatography B, Biomedical sciences and applications 744, 55-64.

Delfino, R.J., Sinha, R., Smith, C., West, J., White, E., Lin, H.J., Liao, S.Y., Gim, J.S., Ma, H.L., Butler, J., Anton-Culver, H., 2000. Breast cancer, heterocyclic aromatic amines from meat and $\mathrm{N}$-acetyltransferase 2 genotype. Carcinogenesis 21, 607-615. 
Evans, R.M., Rahte, S., Kortenkamp, A., 2010. Inability to confirm estrogenicity of the heterocyclic amine $\mathrm{PhIP}$ in two in vitro assays. Toxicology in vitro : an international journal published in association with BIBRA 24, 1757-1763.

Felton, J.S., Knize, M.G., 1991. Occurrence, identification, and bacterial mutagenicity of heterocyclic amines in cooked food. Mutation research 259, 205-217.

Felton, J.S., Knize, M.G., Shen, N.H., Lewis, P.R., Andresen, B.D., Happe, J., Hatch, F.T., 1986. The isolation and identification of a new mutagen from fried ground beef: 2-amino-1-methyl-6-phenylimidazo[4,5-b]pyridine (PhIP). Carcinogenesis 7, 10811086.

Gooderham, N.J., Zhu, H., Lauber, S., Boyce, A., Creton, S., 2002. Molecular and genetic toxicology of 2-amino-1-methyl-6-phenylimidazo[4,5-b]pyridine (PhIP). Mutation research 506-507, 91-99.

Gu, D., Turesky, R.J., Tao, Y., Langouet, S.A., Nauwelaers, G.C., Yuan, J.M., Yee, D., Yu, M.C., 2012. DNA adducts of 2-amino-1-methyl-6-phenylimidazo[4,5b]pyridine and 4-aminobiphenyl are infrequently detected in human mammary tissue by liquid chromatography/tandem mass spectrometry. Carcinogenesis 33, 124-130.

He, L., He, X., Lim, L.P., de Stanchina, E., Xuan, Z., Liang, Y., Xue, W., Zender, L., Magnus, J., Ridzon, D., Jackson, A.L., Linsley, P.S., Chen, C., Lowe, S.W., Cleary, M.A., Hannon, G.J., 2007. A microRNA component of the p53 tumour suppressor network. Nature 447, 1130-1134.

Immonen, E., Serpi, R., Vahakangas, K., Myllynen, P., 2009. Responses of PhIP (2amino-1-methyl-6-phenylimidazo[4,5-b]pyridine) in MCF-7 cells are culture condition dependent. Chemico-biological interactions 182, 73-83.

Ito, N., Hasegawa, R., Sano, M., Tamano, S., Esumi, H., Takayama, S., Sugimura, T., 1991. A new colon and mammary carcinogen in cooked food, 2-amino-1-methyl-6phenylimidazo[4,5-b]pyridine (PhIP). Carcinogenesis 12, 1503-1506.

Kabat, G.C., Cross, A.J., Park, Y., Schatzkin, A., Hollenbeck, A.R., Rohan, T.E., Sinha, R., 2009. Meat intake and meat preparation in relation to risk of postmenopausal breast cancer in the NIH-AARP diet and health study. International journal of cancer Journal international du cancer 124, 2430-2435.

Klinge, C.M., 2012. miRNAs and estrogen action. Trends in endocrinology and metabolism: TEM 23, 223-233.

Koufaris, C., Wright, J., Currie, R.A., Gooderham, N.J., 2012. Hepatic microRNA profiles offer predictive and mechanistic insights after exposure to genotoxic and epigenetic hepatocarcinogens. Toxicological sciences : an official journal of the Society of Toxicology 128, 532-543.

Koufaris, C., Wright, J., Osborne, M., Currie, R.A., Gooderham, N.J., 2013. Time and dose-dependent effects of phenobarbital on the rat liver miRNAome. Toxicology 314, 247-253.

Lauber, S.N., Ali, S., Gooderham, N.J., 2004. The cooked food derived carcinogen 2amino-1-methyl-6-phenylimidazo[4,5-b] pyridine is a potent oestrogen: a mechanistic basis for its tissue-specific carcinogenicity. Carcinogenesis 25, 2509-2517.

Lauber, S.N., Gooderham, N.J., 2007. The cooked meat derived genotoxic carcinogen 2-amino-3-methylimidazo[4,5-b]pyridine has potent hormone-like activity: mechanistic support for a role in breast cancer. Cancer Res 67, 9597-9602.

Lauber, S.N., Gooderham, N.J., 2011. The cooked meat-derived mammary carcinogen 2-amino-1-methyl-6-phenylimidazo[4,5-b]pyridine promotes invasive behaviour of breast cancer cells. Toxicology 279, 139-145.

Lynch, A.M., Knize, M.G., Boobis, A.R., Gooderham, N.J., Davies, D.S., Murray, S., 1992. Intra- and interindividual variability in systemic exposure in humans to 2- 
amino-3,8-dimethylimidazo[4,5-f]quinoxaline and 2-amino-1-methyl- 6phenylimidazo[4,5-b]pyridine, carcinogens present in cooked beef. Cancer research 52, 6216-6223.

Maillot, G., Lacroix-Triki, M., Pierredon, S., Gratadou, L., Schmidt, S., Benes, V., Roche, H., Dalenc, F., Auboeuf, D., Millevoi, S., Vagner, S., 2009. Widespread estrogen-dependent repression of micrornas involved in breast tumor cell growth. Cancer Res 69, 8332-8340.

Manavalan, T.T., Teng, Y., Litchfield, L.M., Muluhngwi, P., Al-Rayyan, N., Klinge, C.M., 2013. Reduced expression of miR-200 family members contributes to antiestrogen resistance in LY2 human breast cancer cells. PloS one 8, e62334.

Mendell, J.T., Olson, E.N., 2012. MicroRNAs in stress signaling and human disease. Cell 148, 1172-1187.

Murray, S., Lynch, A.M., Knize, M.G., Gooderham, M.J., 1993. Quantification of the carcinogens 2-amino-3,8-dimethyl- and 2-amino-3,4,8-trimethylimidazo[4,5f] quinoxaline and 2-amino-1-methyl-6-phenylimidazo[4,5-b]pyridine in food using a combined assay based on gas chromatography-negative ion mass spectrometry. Journal of chromatography 616, 211-219.

Nettles, K.W., Bruning, J.B., Gil, G., Nowak, J., Sharma, S.K., Hahm, J.B., Kulp, K., Hochberg, R.B., Zhou, H., Katzenellenbogen, J.A., Katzenellenbogen, B.S., Kim, Y., Joachmiak, A., Greene, G.L., 2008. NFkappaB selectivity of estrogen receptor ligands revealed by comparative crystallographic analyses. Nature chemical biology 4, 241247.

Okudaira, N., Okamura, T., Tamura, M., Iijma, K., Goto, M., Matsunaga, A., Ochiai, M., Nakagama, H., Kano, S., Fujii-Kuriyama, Y., Ishizaka, Y., 2013. Long interspersed element- 1 is differentially regulated by food-borne carcinogens via the aryl hydrocarbon receptor. Oncogene 32, 4903-4912.

Paris, O., Ferraro, L., Grober, O.M., Ravo, M., De Filippo, M.R., Giurato, G., Nassa, G., Tarallo, R., Cantarella, C., Rizzo, F., Di Benedetto, A., Mottolese, M., Benes, V., Ambrosino, C., Nola, E., Weisz, A., 2012. Direct regulation of microRNA biogenesis and expression by estrogen receptor beta in hormone-responsive breast cancer. Oncogene 31, 4196-4206.

Pinho, F.G., Frampton, A.E., Nunes, J., Krell, J., Alshaker, H., Jacob, J., Pellegrino, L., Roca-Alonso, L., de Giorgio, A., Harding, V., Waxman, J., Stebbing, J., Pchejetski, D., Castellano, L., 2013. Downregulation of microRNA-515-5p by the estrogen receptor modulates sphingosine kinase 1 and breast cancer cell proliferation. Cancer research 73, 5936-5948.

Qin, C., Nguyen, T., Stewart, J., Samudio, I., Burghardt, R., Safe, S., 2002. Estrogen up-regulation of p53 gene expression in MCF-7 breast cancer cells is mediated by calmodulin kinase IV-dependent activation of a nuclear factor kappaB/CCAATbinding transcription factor-1 complex. Molecular endocrinology 16, 1793-1809.

Rhomberg, L.R., Goodman, J.E., 2012. Low-dose effects and nonmonotonic doseresponses of endocrine disrupting chemicals: has the case been made? Regulatory toxicology and pharmacology : RTP 64, 130-133.

Rindgen, D., Turesky, R.J., Vouros, P., 1995. Determination of in vitro formed DNA adducts of 2-amino-1-methyl-6-phenylimidazo[4,5-b]pyridine using capillary liquid chromatography/electrospray ionization/tandem mass spectrometry. Chemical research in toxicology 8, 1005-1013.

Shimono, Y., Zabala, M., Cho, R.W., Lobo, N., Dalerba, P., Qian, D., Diehn, M., Liu, H., Panula, S.P., Chiao, E., Dirbas, F.M., Somlo, G., Pera, R.A., Lao, K., Clarke, 
M.F., 2009. Downregulation of miRNA-200c links breast cancer stem cells with normal stem cells. Cell 138, 592-603.

Sinha, R., Gustafson, D.R., Kulldorff, M., Wen, W.Q., Cerhan, J.R., Zheng, W., 2000. 2-amino-1-methyl-6-phenylimidazo[4,5-b]pyridine, a carcinogen in high-temperaturecooked meat, and breast cancer risk. Journal of the National Cancer Institute 92, 1352-1354.

Song, S.J., Poliseno, L., Song, M.S., Ala, U., Webster, K., Ng, C., Beringer, G., Brikbak, N.J., Yuan, X., Cantley, L.C., Richardson, A.L., Pandolfi, P.P., 2013. MicroRNA-antagonism regulates breast cancer stemness and metastasis via TETfamily-dependent chromatin remodeling. Cell 154, 311-324.

Soto, A.M., Chung, K.L., Sonnenschein, C., 1994. The pesticides endosulfan, toxaphene, and dieldrin have estrogenic effects on human estrogen-sensitive cells. Environmental health perspectives 102, 380-383.

Srivastava, N., Manvati, S., Srivastava, A., Pal, R., Kalaiarasan, P., Chattopadhyay, S., Gochhait, S., Dua, R., Bamezai, R.N., 2011. miR-24-2 controls H2AFX expression regardless of gene copy number alteration and induces apoptosis by targeting antiapoptotic gene BCL-2: a potential for therapeutic intervention. Breast cancer research : BCR 13, R39.

Steck, S.E., Gaudet, M.M., Eng, S.M., Britton, J.A., Teitelbaum, S.L., Neugut, A.I., Santella, R.M., Gammon, M.D., 2007. Cooked meat and risk of breast cancer-lifetime versus recent dietary intake. Epidemiology 18, 373-382.

Taylor, E.F., Burley, V.J., Greenwood, D.C., Cade, J.E., 2007. Meat consumption and risk of breast cancer in the UK Women's Cohort Study. British journal of cancer 96, 1139-1146.

Turteltaub, K.W., Dingley, K.H., Curtis, K.D., Malfatti, M.A., Turesky, R.J., Garner, R.C., Felton, J.S., Lang, N.P., 1999. Macromolecular adduct formation and metabolism of heterocyclic amines in humans and rodents at low doses. Cancer letters 143, 149-155.

Vandenberg, L.N., Colborn, T., Hayes, T.B., Heindel, J.J., Jacobs, D.R., Jr., Lee, D.H., Shioda, T., Soto, A.M., vom Saal, F.S., Welshons, W.V., Zoeller, R.T., Myers, J.P., 2012. Hormones and endocrine-disrupting chemicals: low-dose effects and nonmonotonic dose responses. Endocrine reviews 33, 378-455.

Venugopal, M., Callaway, A., Snyderwine, E.G., 1999. 2-Amino-1-methyl-6phenylimidazo[4,5-b]pyridine (PhIP) retards mammary gland involution in lactating Sprague-Dawley rats. Carcinogenesis 20, 1309-1314.

Villalobos, M., Olea, N., Brotons, J.A., Olea-Serrano, M.F., Ruiz de Almodovar, J.M., Pedraza, V., 1995. The E-screen assay: a comparison of different MCF7 cell stocks. Environmental health perspectives 103, 844-850.

Wickramasinghe, N.S., Manavalan, T.T., Dougherty, S.M., Riggs, K.A., Li, Y., Klinge, C.M., 2009. Estradiol downregulates miR-21 expression and increases miR21 target gene expression in MCF-7 breast cancer cells. Nucleic acids research 37, 2584-2595.

Yadollahi-Farsani, M., Gooderham, N.J., Davies, D.S., Boobis, A.R., 1996. Mutational spectra of the dietary carcinogen 2-amino-1-methyl-6- phenylimidazo[4,5b]pyridine(PhIP) at the Chinese hamsters hprt locus. Carcinogenesis 17, 617-624.

Yang, Y., Wang, L.L., Wang, H.X., Guo, Z.K., Gao, X.F., Cen, J., Li, Y.H., Dou, L.P., Yu, L., 2013. The epigenetically-regulated miR-663 targets H-ras in K-562 cells. The FEBS journal 280, 5109-5117. 
Yu, M., Snyderwine, E.G., 2002. H-ras oncogene mutations during development of 2amino-1-methyl-6-phenylimidazo[4,5-b]pyridine ( $\mathrm{PhIP}$ )-induced rat mammary gland cancer. Carcinogenesis 23, 2123-2128.

Yu, X., Zhang, X., Dhakal, I.B., Beggs, M., Kadlubar, S., Luo, D., 2012. Induction of cell proliferation and survival genes by estradiol-repressed microRNAs in breast cancer cells. BMC cancer 12, 29.

Zhao, K., Murray, S., Davies, D.S., Boobis, A.R., Gooderham, N.J., 1994. Metabolism of the food derived mutagen and carcinogen 2-amino-1-methyl-6phenylimidazo(4,5-b)pyridine (PhIP) by human liver microsomes. Carcinogenesis 15, 1285-1288. 
Table 1 miRNA responsive to PhIP $\left(10^{-7} \mathrm{M}\right)$ treatment of MCF-7 cells

\begin{tabular}{|l|l|l|l|l|}
\hline miRNA & 4 hours & 8 hours & 12 hours & 24 hours \\
\hline miR-1 & $0.8 \pm 0.05$ & $1.0 \pm 0.16$ & $\underline{0.6 \pm 0.07}$ & $1.1 \pm 0.52$ \\
\hline miR-106b & $0.8 \pm 0.02$ & $0.7 \pm 0.04$ & $0.8 \pm 0.07$ & $\underline{0.6 \pm 0.09}$ \\
\hline miR-141 & $0.8 \pm 0.09$ & $0.8 \pm 0.05$ & $0.9 \pm 0.10$ & $\underline{0.6 \pm 0.13}$ \\
\hline miR-16 & $0.8 \pm 0.10$ & $\underline{0.6 \pm 0.05}$ & $0.7 \pm 0.07$ & $\underline{0.6 \pm 0.16}$ \\
\hline miR-200c & $0.8 \pm 0.14$ & $0.7 \pm 0.7$ & $0.8 \pm 0.11$ & $\underline{0.6 \pm 0.18}$ \\
\hline miR-21 & $0.7 \pm 0.12$ & $\underline{0.6 \pm 0.05}$ & $0.7 \pm 0.05$ & $\underline{0.5 \pm 0.13}$ \\
\hline miR-24 & $0.8 \pm 0.10$ & $0.7 \pm 0.05$ & $0.8 \pm 0.08$ & $\underline{0.6 \pm 0.16}$ \\
\hline miR-26a & $0.8 \pm 0.10$ & $0.7 \pm 0.05$ & $0.8 \pm 0.08$ & $\underline{0.6 \pm 0.16}$ \\
\hline miR-30d & $0.8 \pm 0.12$ & $0.7 \pm 0.03$ & $0.8 \pm 0.09$ & $\underline{0.6 \pm 0.14}$ \\
\hline miR-330-5p & $\underline{0.5 \pm 0.01}$ & $\underline{0.6 \pm 0.05}$ & $\underline{0.6 \pm 0.01}$ & $\underline{0.6 \pm 0.03}$ \\
\hline miR-494 & $\underline{1.6 \pm 0.18}$ & $\underline{1.5 \pm 0.10}$ & $2.0 \pm 0.58$ & $1.4 \pm 0.25$ \\
\hline miR-518c ${ }^{*}$ & $\underline{0.6 \pm 0.05}$ & $\underline{0.6 \pm 0.04}$ & $0.7 \pm 0.08$ & $\underline{0.6 \pm 0.06}$ \\
\hline miR-574-3p & $1.3 \pm 0.15$ & $1.4 \pm 0.10$ & $1.2 \pm 0.23$ & $\underline{1.7 \pm 0.20}$ \\
\hline miR-574-5p & $\underline{1.7 \pm 0.14}$ & $\underline{1.7 \pm 0.29}$ & $\underline{1.6 \pm 0.21}$ & $\underline{2.0 \pm 0.33}$ \\
\hline miR-612 & $\underline{0.6 \pm 0.01}$ & $0.7 \pm 0.02$ & $0.7 \pm 0.05$ & $0.8 \pm 0.09$ \\
\hline miR-615-5p & $\underline{0.6 \pm 0.04}$ & $\underline{0.6 \pm 0.01}$ & $0.7 \pm 0.05$ & $\underline{0.6 \pm 0.01}$ \\
\hline miR-638 & $\underline{0.5 \pm 0.04}$ & $\underline{0.5 \pm 0.03}$ & $0.8 \pm 0.29$ & $\underline{0.6 \pm 0.03}$ \\
\hline miR-654-5p & $\underline{0.6 \pm 0.03}$ & $0.7 \pm 0.03$ & $0.7 \pm 0.05$ & $0.7 \pm 0.05$ \\
\hline miR-663 & $\underline{0.4 \pm 0.01}$ & $\underline{0.5 \pm 0.04}$ & $\underline{0.6 \pm 0.15}$ & $\underline{0.5 \pm 0.03}$ \\
\hline miR-801 ${ }^{a}$ & $\underline{0.6 \pm 0.03}$ & $\underline{0.6 \pm 0.03}$ & $\underline{0.6 \pm 0.01}$ & $\underline{0.6 \pm 0.03}$ \\
\hline miR-923 ${ }^{a}$ & $\underline{2.2 \pm 0.09}$ & $\underline{2.0 \pm 0.08}$ & $\underline{3.1 \pm 0.82}$ & $\underline{2.5 \pm 0.40}$ \\
\hline
\end{tabular}

The miRNA listed here are those with a fold change at least 1.5-fold change and two standard deviations from vehicle-treated cells in one or more time-points. Mean fold change in PhIP treated cells compared to vehicle treated cells and standard deviation are shown. Underlined are data fulfilling criteria.

${ }^{a}$ MiRBase (version 20) indicates that these are wrongly classified as miRs. 
Table 2 miRNA responsive to E2 $\left(10^{-8} \mathrm{M}\right)$ treatment of MCF-7 cells.

\begin{tabular}{|c|c|c|c|c|}
\hline miRNA & 4 hours & 8 hours & 12 hours & 24 hours \\
\hline miR-1226* & $\underline{0.6 \pm 0.01}$ & $0.7 \pm 0.02$ & $0.7 \pm 0.13$ & $0.7 \pm 0.02$ \\
\hline miR-1228* & $0.6 \pm 0.04$ & $0.6 \pm 0.05$ & $1.1 \pm 0.71$ & $0.6 \pm 0.07$ \\
\hline miR-1229 & $1.4 \pm 0.2$ & $1.3 \pm 0.13$ & $1.1 \pm 0.25$ & $1.7 \pm 0.26$ \\
\hline miR-1233 & $1.4 \pm 0.21$ & $1.3 \pm 0.15$ & $1.2 \pm 0.21$ & $1.6 \pm 0.29$ \\
\hline miR-141 & $0.9 \pm 0.09$ & $0.9 \pm 0.02$ & $0.9 \pm 0.09$ & $\underline{0.6 \pm 0.16}$ \\
\hline miR-149* & $0.7 \pm 0.07$ & $0.6 \pm 0.03$ & $1.2 \pm 0.80$ & $\underline{0.6 \pm 0.6}$ \\
\hline miR-150* & $\underline{0.6 \pm 0.02}$ & $\underline{0.6 \pm 0.01}$ & $\underline{0.6 \pm 0.10}$ & $\underline{0.6 \pm 0.16}$ \\
\hline miR-197 & $1.5 \pm 0.14$ & $1.4 \pm 0.10$ & $1.1 \pm 0.21$ & $1.6 \pm 0.14$ \\
\hline miR-21 & $0.7 \pm 0.10$ & $0.7 \pm 0.02$ & $0.7 \pm 0.06$ & $\underline{0.6 \pm 0.14}$ \\
\hline miR-330-5p & $\underline{0.5 \pm 0.01}$ & $\underline{0.6 \pm 0.05}$ & $\underline{0.6 \pm 0.04}$ & $0.5 \pm 0.02$ \\
\hline miR-34b & $1.4 \pm 0.06$ & $1.4 \pm 0.06$ & $1.2 \pm 0.23$ & $1.6 \pm 0.14$ \\
\hline$m i R-518 c^{*}$ & $\underline{0.6 \pm 0.05}$ & $\underline{0.6 \pm 0.04}$ & $\underline{0.6 \pm 0.06}$ & $\underline{0.6 \pm 0.06}$ \\
\hline$m i R-574-3 p$ & $1.4 \pm 0.2$ & $1.3 \pm 0.17$ & $1.3 \pm 0.18$ & $1.7 \pm 0.23$ \\
\hline$m i R-574-5 p$ & $1.7 \pm 0.16$ & $1.6 \pm 0.29$ & $1.5 \pm 0.25$ & $\underline{2.0 \pm 0.20}$ \\
\hline miR-585 & $\underline{0.6 \pm 0.03}$ & $0.7 \pm 0.04$ & $0.9 \pm 0.25$ & $\underline{0.6 \pm 0.05}$ \\
\hline miR-595 & $1.4 \pm 0.10$ & $1.2 \pm 0.12$ & $1.2 \pm 0.20$ & $1.6 \pm 0.29$ \\
\hline miR-612 & $\underline{0.6 \pm 0.02}$ & $0.7 \pm 0.01$ & $0.7 \pm 0.05$ & $0.7 \pm 0.04$ \\
\hline miR-615-5p & $\underline{0.6 \pm 0.03}$ & $0.7 \pm 0.04$ & $\underline{0.6 \pm 0.03}$ & $0.6 \pm 0.02$ \\
\hline miR-638 & $0.4 \pm 0.04$ & $0.4 \pm 0.03$ & $0.7 \pm 0.34$ & $\underline{0.3 \pm 0.03}$ \\
\hline miR-654-5p & $\underline{0.6 \pm 0.02}$ & $0.7 \pm 0.03$ & $0.7 \pm 0.03$ & $\underline{0.6 \pm 0.03}$ \\
\hline miR-663 & $0.3 \pm 0.01$ & $\underline{0.4 \pm 0.04}$ & $0.4 \pm 0.17$ & $\underline{0.3 \pm 0.03}$ \\
\hline miR-671-5p & $0.7 \pm 0.03$ & $0.7 \pm 0.01$ & $0.8 \pm 0.09$ & $\underline{0.6 \pm 0.05}$ \\
\hline miR-766 & $1.7 \pm 0.55$ & $1.4 \pm 0.37$ & $1.4 \pm 0.47$ & $2.3 \pm 0.61$ \\
\hline $\mathrm{miR}-801^{\mathrm{a}}$ & $0.7 \pm 0.03$ & $\underline{0.6 \pm 0.03}$ & $\underline{0.6 \pm 0.07}$ & $0.7 \pm 0.05$ \\
\hline miR-885-5p & $1.3 \pm 0.10$ & $1.3 \pm 0.05$ & $1.2 \pm 0.31$ & $1.6 \pm 0.26$ \\
\hline $\mathrm{miR}-923^{\mathrm{a}}$ & $\underline{2.2 \pm 0.09}$ & $\underline{2.0 \pm 0.08}$ & $\underline{2.8 \pm 0.98}$ & $\underline{2.0 \pm 0.19}$ \\
\hline$m i R-92 b^{*}$ & $0.5 \pm 0.04$ & $0.5 \pm 0.04$ & $0.9 \pm 0.65$ & $\underline{0.5 \pm 0.03}$ \\
\hline
\end{tabular}

The miRNA listed here are those with a fold change at least 1.5-fold change and two standard deviations from vehicle-treated cells in one or more time-points. Mean fold change in E2 treated cells compared to vehicle treated cells and standard deviation are shown. Underlined are data fulfilling criteria.

${ }^{a}$ MiRBase (version 20) indicates that these are wrongly classified as miRs. 


\section{Figure Legends}

Fig.1 Effect of PhIP and E2 on proliferation of MCF-7 cells (A) PhIP-treated cells compared to negative control; (B) E2-treated cells compared to negative control. Values are mean with standard deviation * $p<0.05{ }^{* *} p<0.01 ; n=3$ (ANOVA)

Fig.2 Verification of miRNA microarray data and clustering analysis (A) Each box plot on the $x$-axis represents a treatment sample and data points are individual microRNAs; (B) Hierarchical clustering analysis of microarray samples from PhIP $\left(P, 10^{-7} \mathrm{M}\right)$ and E2 $\left(\mathrm{E}, 10^{-8} \mathrm{M}\right)$ treated MCF-7 cells; (C) Comparison of qRT-PCR and microarray data for miR-663; (D) Comparison of qRT-PCR and microarray data for miR-638. Pearson's correlation $(r)$ is shown.

Fig.3 Comparison of effects of PhIP $\left(10^{-7} \mathrm{M}\right)$ and E2 $\left(10^{-8} \mathrm{M}\right)$ treatment on miRNA expression in MCF-7 cell line at different time-points (A) after 4 hours; (B) after 8 hours; (C) after 12 hours; (D) after 24 hours. Each oval represents a time-point of treatment. MiRNA responsive to both E2 and PhIP are shown in the intersection region of ovals. MiRNA with downregulated expression are depicted as underlined.

Fig.4 Heatmap displaying averaged expression of miRNA responsive to E2 or PhIP with time of treatment. MiRNA with increased expression compared to vehicle treated cells are shown in red, those with decreased expression are shown in green, black colour indicates no change in expression compared to control. 
Figure 1

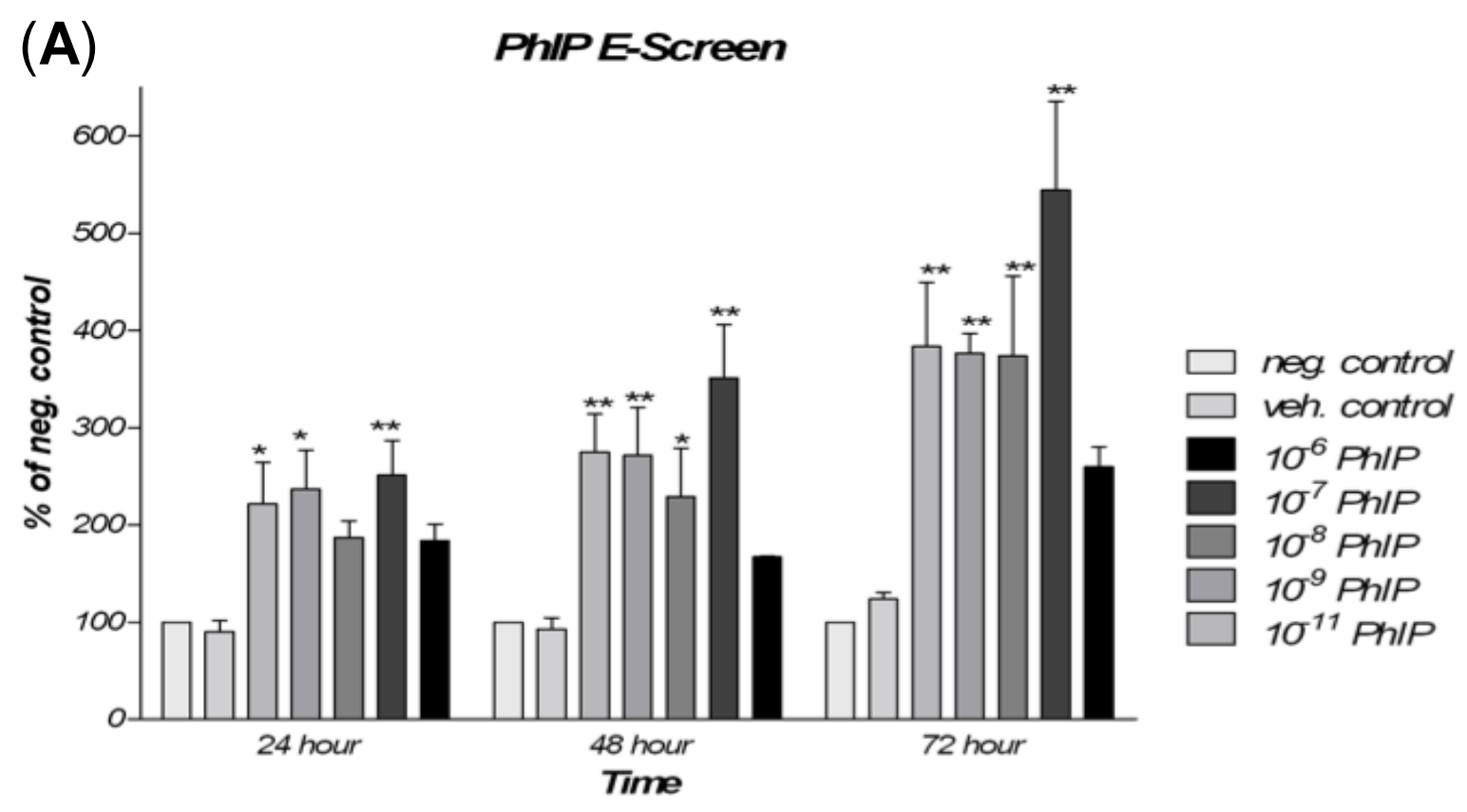

(B)

17- $\beta$ Estradiol E-Screen

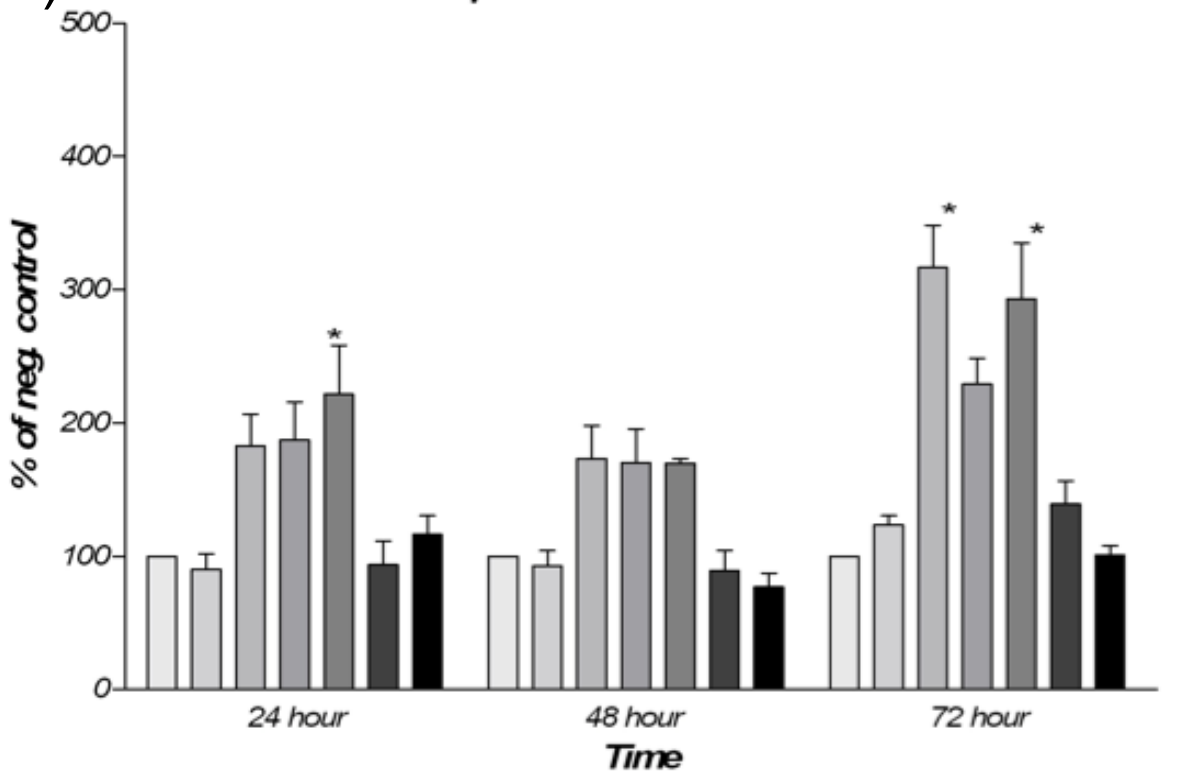

Fig.1 
(A)

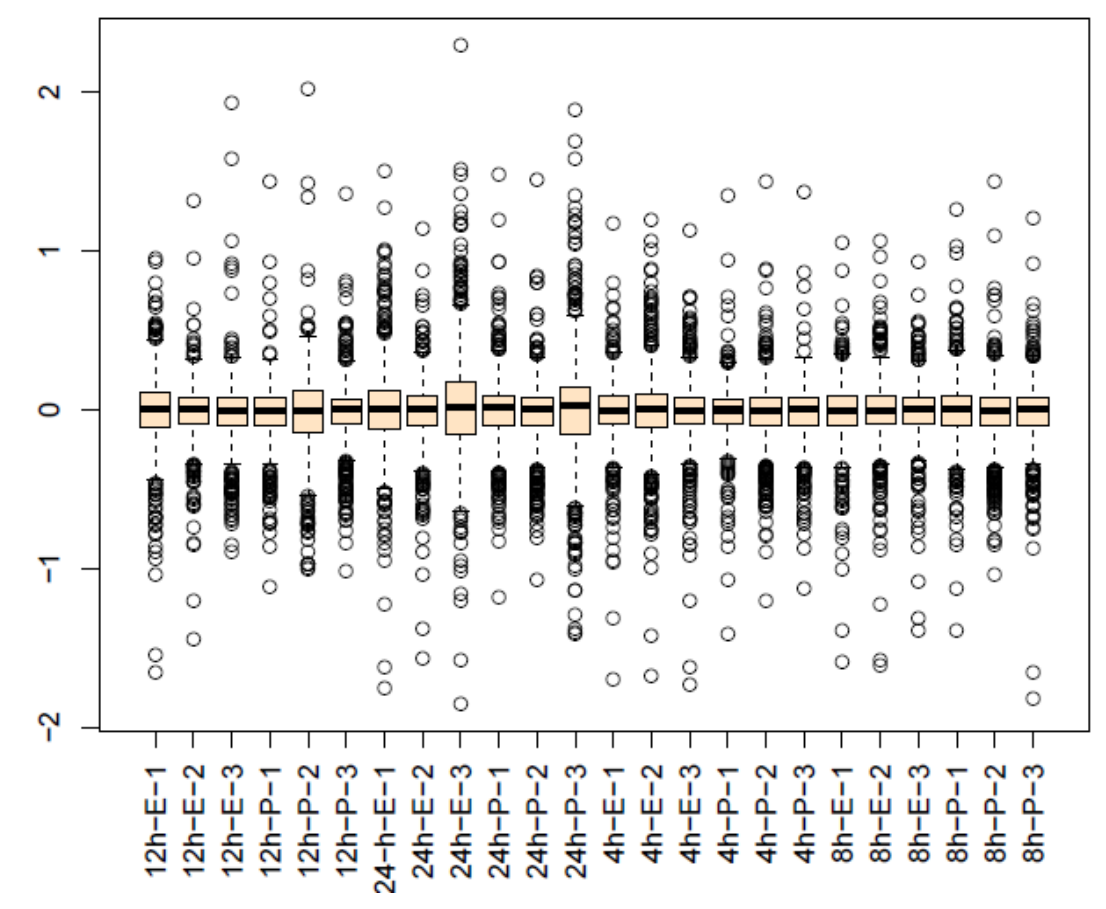

(C)

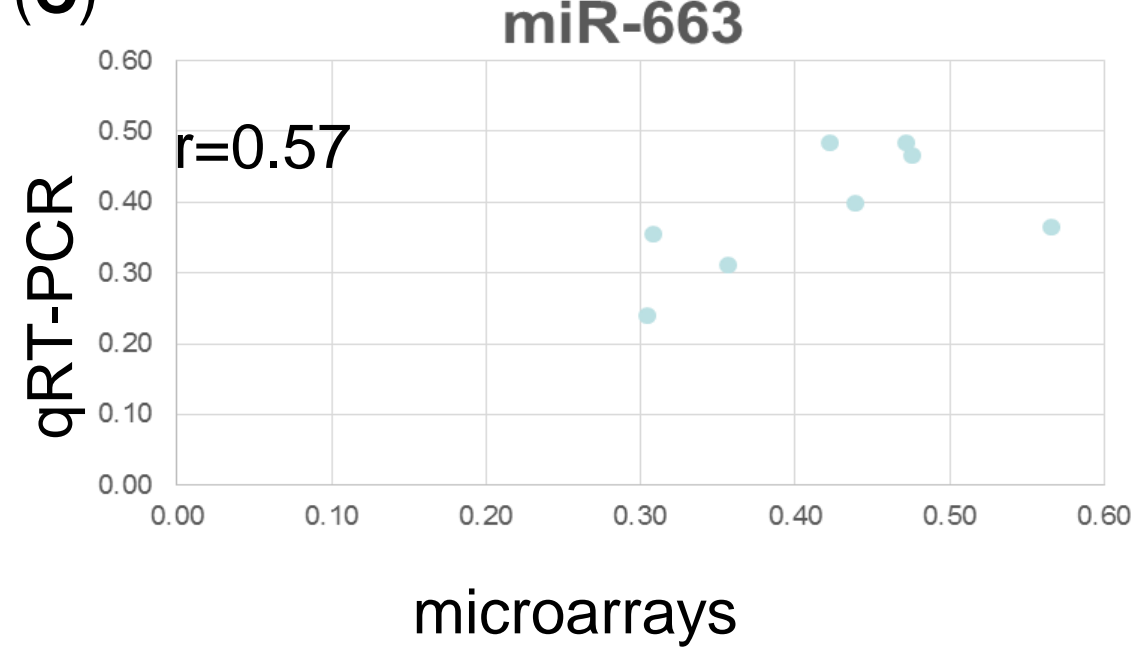

(B)

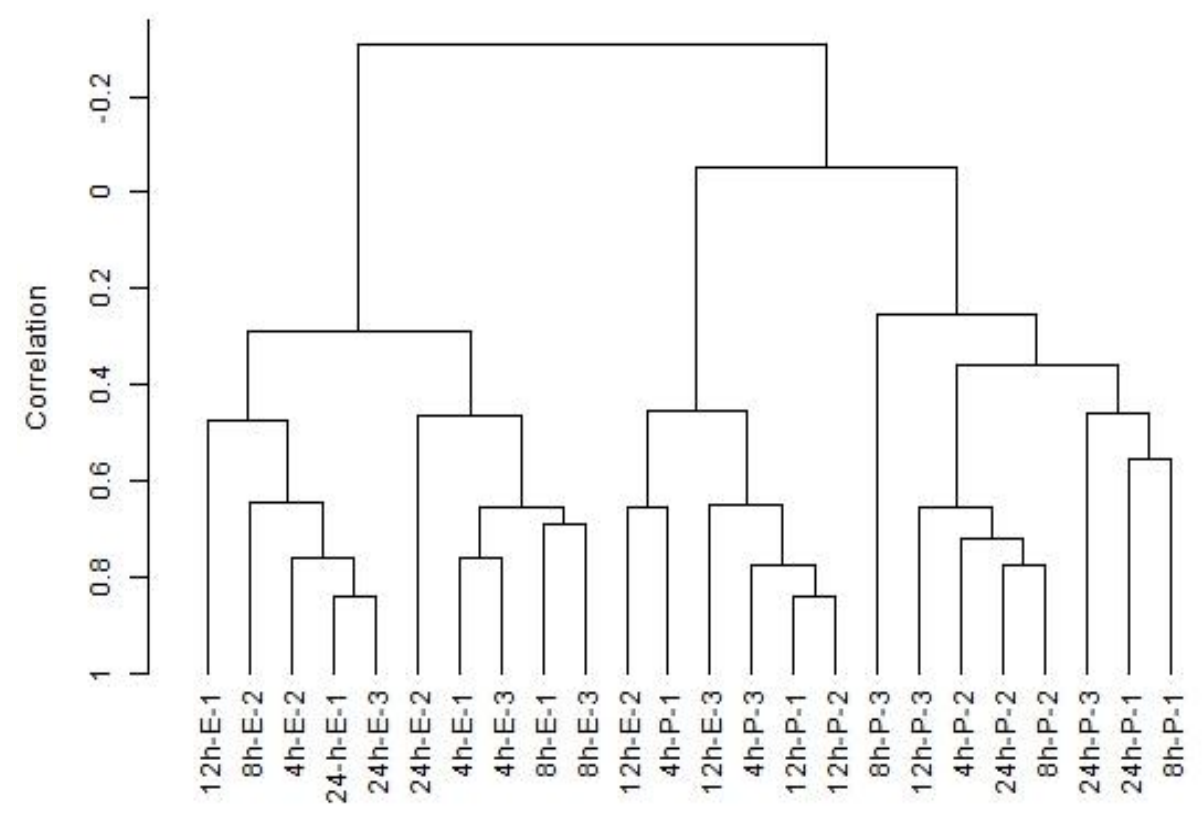

(D)

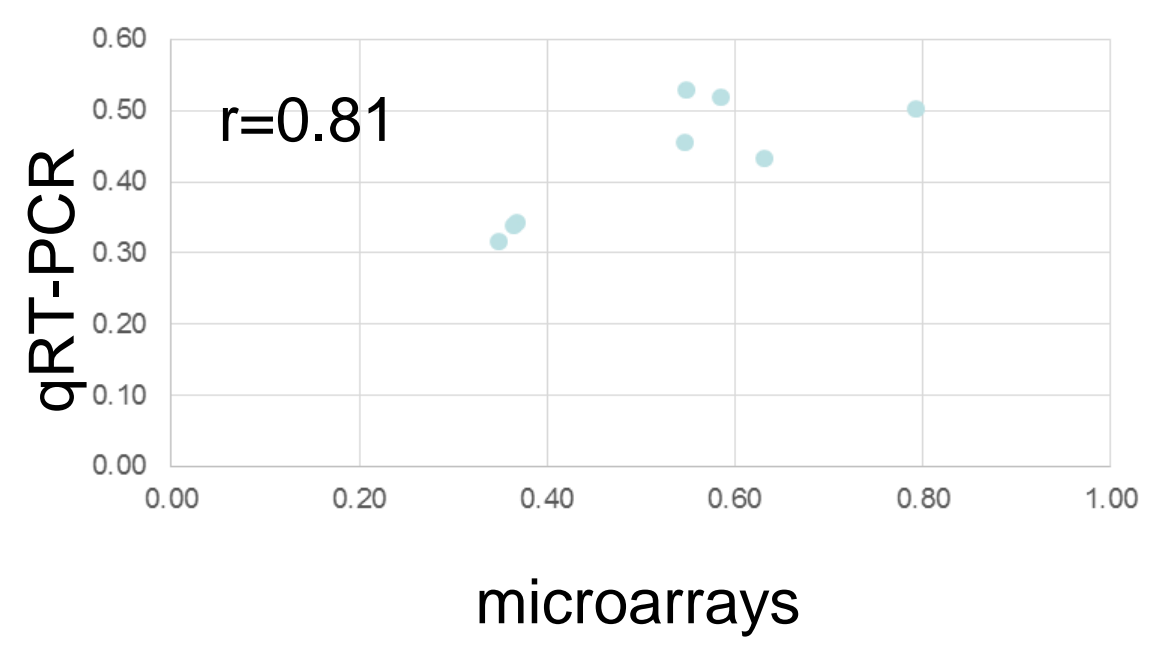

\section{Fig.2}


Figure 3 modified
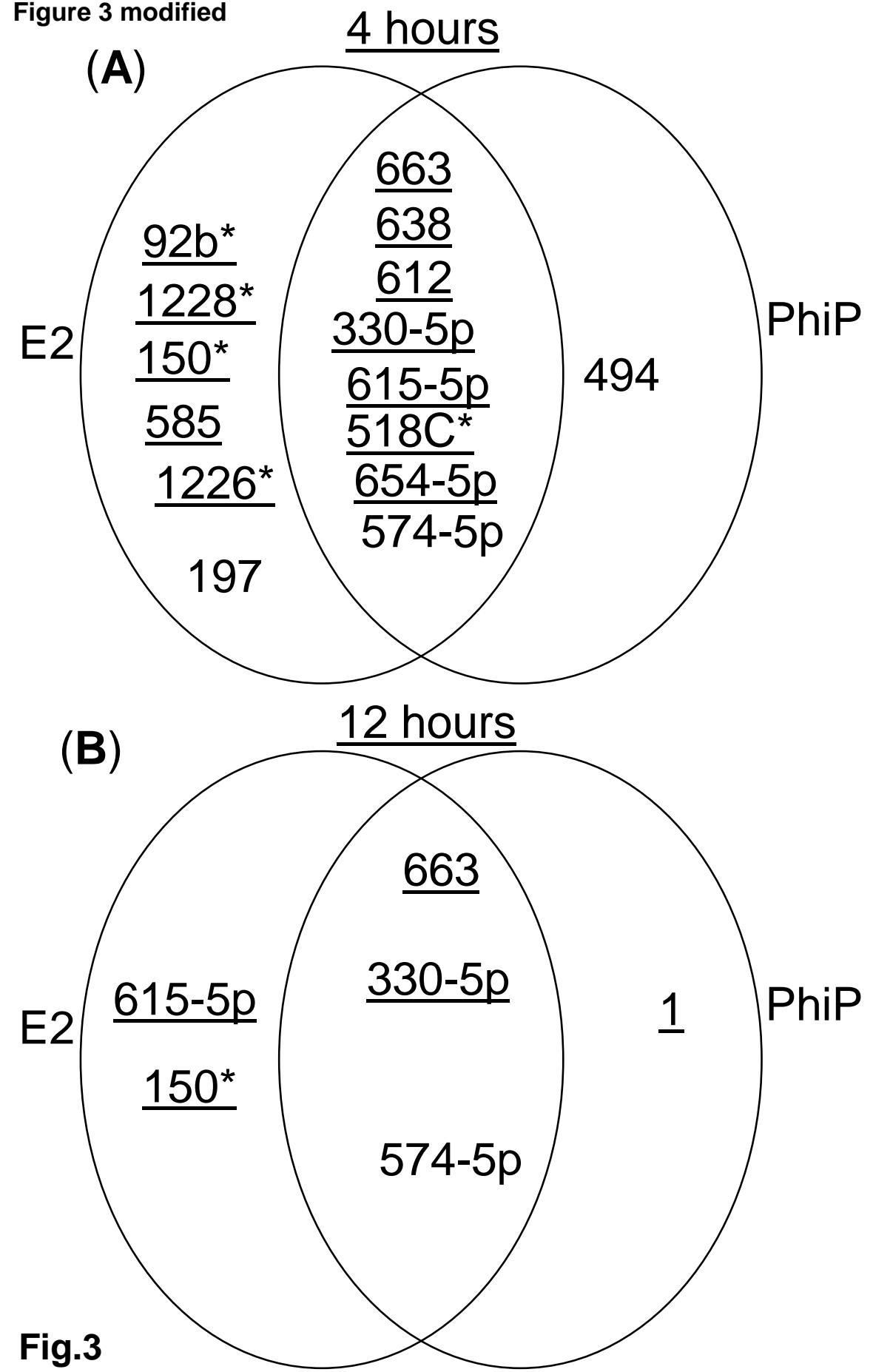

8 hours
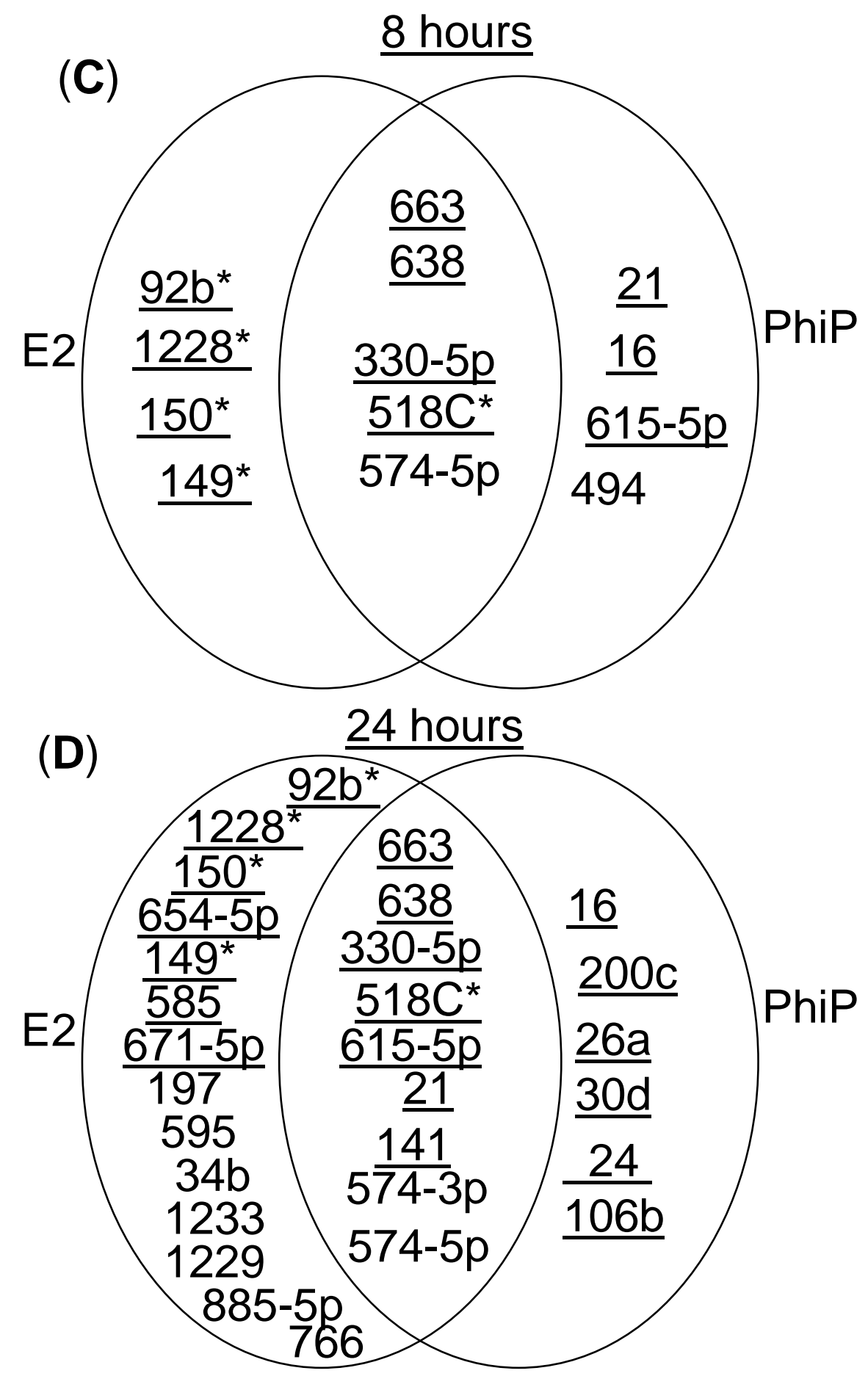


\section{E2 PhiP}

481224481224 Time

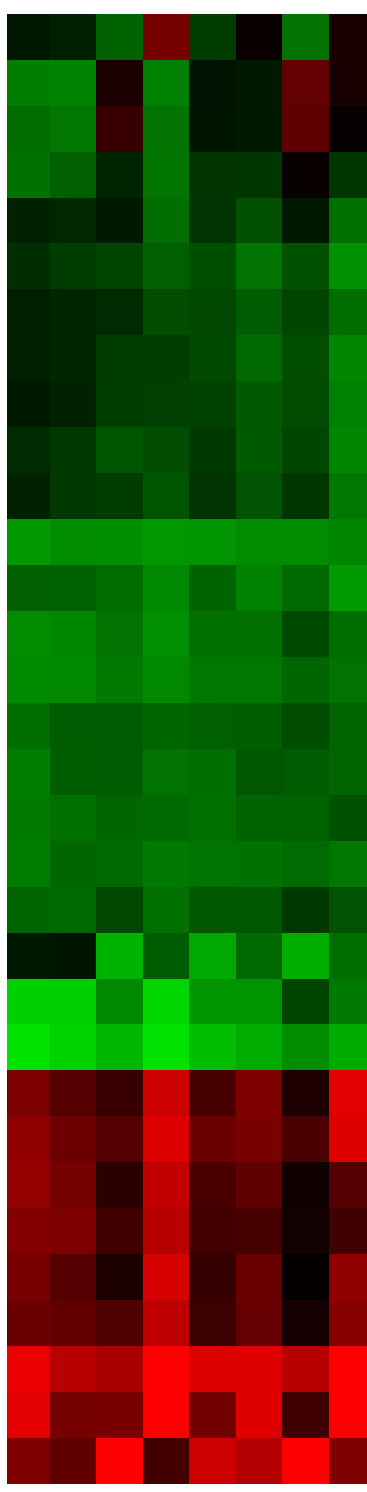

GE hsa-miR-1

GE hsa-miR-1228*

GE hsa-miR-149*

GE hsa-miR-585

GE hsa-miR-141

GE hsa-miR-16

GE hsa-miR-106b

GE hsa-miR-26a

GE hsa-miR-30d

GE hsa-miR-200c

GE hsa-miR-24

GE hsa-miR-330-5p

GE hsa-miR-21

GE hsa-miR-150*

GE hsa-miR-518c *

GE hsa-miR-1226*

GE hsa-miR-654-5p

GE hsa-miR-612

GE hsa-miR-615-5n

GE hsa-miR-671-5p

GE hsa-miR-92b*

GE hsa-miR-638

GE hsa-miR-663

GE hsa-miR-1233

GE hsa-miR-574-3p

GE hsa-miR-197

GE hsa-miR-34b

GE hsa-miR-1229

GE hsa-miR-885-5n

GE hsa-miR-574-5p

GE hsa-miR-766

GE_hsa-miR-494 